\title{
The use of Java applets as a new pedagogical tool in teaching undergraduate physics
}

\author{
P. Ramalingam \\ Department of Mathematics and Natural Sciences, \\ The American University of Iraq, Sulaimani, Iraq
}

\begin{abstract}
By adopting the current conventional methods of teaching, an instructor will only be able to engage a select group of students in his/her class. In order to actively engage the class of students for the entire time period of the lecture and also to keep them motivated, the instructor can try to adopt a selection of different pedagogical methods such as the use of multimedia (Java applets) and also a classroom response pad or Clickers (Interactive Response System). For teaching some concepts in physics in a class, an instructor employs several demonstration equipment or display tools to ease in the learning. Utilizing commercially available or off the shelf demonstration equipment has been very expensive and time consuming and most often ineffective. Herein we try to intuit students to use available open source software to produce well designed Java applets. Designing applets or Physlets ${ }^{\mathrm{TM}}$ have been used during lectures and have been further evaluated on the effectiveness of using them in our lectures. Results from this study have been very encouraging and subsequently it has created keen interest amongst the rest of the class of students to design similar applets. Such exercises will develop in them the necessary critical thinking and presentation skills. The paper will present a demonstration of some applets that can be adopted for the teaching to be more effective.

Keywords: Java applets, clickers, class room response pads, Faraday's Law, Physlets, teaching pedagogy.
\end{abstract}

\section{Introduction}

A new and a formative urban city needs to have its own strong human capital and secondly a learning community that builds these human capacity resources. 
This will bring about the much need self sustaining urban development. Capital investment in the universities and tertiary institutions are to produce quality graduates equipped with the necessary traits and skills sets. Multinational firms will seek indigenous talent before considering on their investments. Iraq has natural resources and in order to turn those resources into value added goods, there is a need for a stronger sciences, engineering and technology talent. Hence a more engaged and heuristic teaching method needs to be adopted to build graduates in Sciences and Engineering. Premier institutions offering civil, structural, mechanical and electrical and electronics engineering education need to be produce quality graduates with critical thinking skills and creative talents.

Typical classroom teaching one can retain interest only in about half the students and moreover once student achieve saturation level it is very difficult to cover material in more than half the class are not with you. Hence a model lesson plan for Faraday's Law has been designed. In this lesson plan, initially a Java applet or a short video is to be screened during the lecture and it follows a small class room discussion on it. The ensuing group discussions and peer teaching can be chartered to identify and narrow the areas where the physical phenomena needs to be conceptualize. The developed Java applets were evaluated by introducing in two different classes, in the first one class before a conventional lecture is to be performed and for the second class after the topic was taught using the prescribed text and power points. There is a striking difference between the two classes and the outcomes from their survey are to be presented in this paper.

\subsection{Current methods of teaching}

In recent years, physics education researchers and cognitive psychologists have turned their attention to the question of how individuals solve basic physics problems. The author feels that mastering problem solving do not always conclude that students have a good conceptual understanding of physics. Student often are allowed to use a given formulae sheet and hence it enables them to try out some of the straight forward and simple substitution problems easily. They can also solve more challenging problems by listing out the given variables and search for the right formula and get to the final answer, without any actual understanding of the exercise problem.

\subsubsection{Teaching physics concepts - styles of delivery}

Concepts in physics are rather tough and hence students need a great deal of assistance. Physical concepts can be fully understood only if the students are able to solve some problems on their own. Given the amount of time available for an undergraduate course, the instructor has to be innovative, and try to seek a balance between how much time one spends on teaching concepts and in the use of teaching aids and solving numerical problems. Teaching aids often don't convey the concepts and sometimes can mislead the class. Java applets that are available on the open source websites have given us the creative effort to do some in house development of it. We modified and tested two such applets and have used it for the years 2011 and 2012, to evaluate it as a teaching aid. These 
applets have created a lot of interest amongst the students and have brought out their critical thinking skills. It has also helped in cementing more strongly and hence they are able to attempt problems in these areas. Physics is a capstone course for most undergraduate programs especially it gives the essential foundation to all higher level Engineering courses. Nursing and physiotherapy undergraduate program programs also have two courses of conceptual physical science and non science majors also have to take these courses in a liberal arts setting.

\section{Conceptual understanding using problem solving}

The ability to solve problems (especially in undergraduate physics) is a basic life skill and is highly essential to understanding technical subjects. Problem-solving is a subset of critical thinking and employs the same strategies. Problem solving in physics helps students to digest the physical concepts and possibly relate them to some events in life. In general, the goal of problem-solving is to adduce correct solutions to well structured problems, whereas the goal of critical thinking is to construct and defend reasonable solutions to ill-structured problems.

Basically, problem-solving is the process of reasoning to solutions using more than simple application of previously learned procedures. There are several reasons those college students often fail to reach a satisfactory level of proficiency in problem-solving. They frequently suffer from fears and anxieties especially fear of failure in exams, which hampers their efforts to solve problems. Some students have independent learning styles which makes it harder for such student to learn how to solve exercise problems. These students are expected to do a more conventional approach or general thinking patterns which may inhibit also their problem-solving ability when it comes to a problem which requires critical thinking skills.

\subsection{Some known problem solving models}

Studies of novice and expert physics problem solvers have suggest that there are two distinct and contrasting patterns of problem solving among experts and novices. These variations have led to the formulation of two major models for problem solving. According to Larkin et al. [1] expert problem solving is typified by the KD model, the so-called knowledge-development approach.

Novice problem solving is typified by the ME model, the so-called means-end approach. In the ME model the student typically works "backward" from the unknown to the given information. Under this scenario the novice problem solver (NPS) essentially writes an equation and then associates each term in the equation with a value from the problem. If there are additional unknowns, the problem solver moves on to the next equation.

In the KD model the expert proceeds in the opposite direction, working forward from the given information. Under this second scenario, the expert problem solver (EPS) associates each of the known physical quantities with each 
term of the equation as the equation is set up. That is, novices move from equations to variables, while the experts move from the variables to the equation.

\subsubsection{Some analytical approaches to problem solving}

The research in the area of physics problem solving accelerated rapidly in the early 1980s and is now the focus of attention in the research literature. There are a number of questions left unresolved, including those given by Maloney [2], "What knowledge do novices typically use when faced with physics problems?" and "How is the knowledge that a novice possesses organized in memory?" and "How do alternative conceptions affect novices' representations?" However important these questions, the basis of this research still depends upon the answer to the question, "How do problem-solving approaches differ between novice and experts?"

Below, we examine these problems and explore several strategies that students and instructors can use to address them. Different learning styles as well as gender-specific differences in thinking can be addressed by employing a variety of activities and approaches in teaching. The traditional instructional mode of lecturing and explaining is effective for only one learning style. To address other learning styles, you might use graphics to illustrate concepts, provide opportunities for practice in class, ask for student interpretations of data, and require students to work on problems in groups and making students aware of their learning styles.

When queried, student expressed the opinion that they had learned general problem-solving strategies prior to taking the physics class mentioned in this study. One student attributed his physics problem-solving skill to a high school classmate; another to life experiences; and yet another to related regular coursework in other classes. Students generally felt that their problem-solving skills were enhanced by taking the physics course, and this helped them to gain a broader perspective on the problem-solving process. There was a general consensus that the instructors did very little to help students learn the fundamental intellectual processes of mathematical problem solving in physics

\section{Java applets as a teaching or learning study tool}

Java applets are available on the web at http://www.compadre.org/osp/ (easy Java open source software). Such chosen applets are displayed before the lecture on the topic. It gets the class into discussion mode and the critical thinking skills are brought into play. It is difficult to obtain off the shelf demonstration equipment to our remote places where a more engaged teaching method. Some of the students have started to use the open source software to create and adapt in-house Java applets for difficult physics concepts as an assignment exercise.

All undergraduate courses in engineering and physical sciences have to pursue a sequence of two calculus based physics courses and the second of that course talks about electricity and magnetism. Coulomb’s Inverse Square Law in electrostatics and in electromagnetism, a more complex time dependant Faraday's Law are some very important physical concepts for which we 
introduced Java applets. The applets were shown to the students before they were exposed to the concept and later we teach the concept using text book.

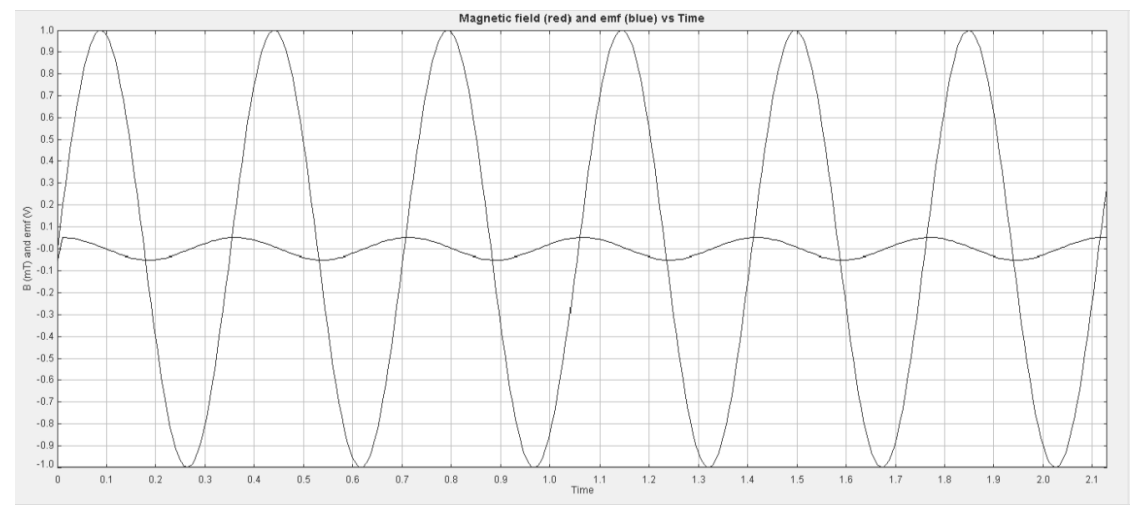

Figure 1: Screen shot of a Java applet simulation for Faraday's Law of Electromagnetic Induction (high amplitude lines-magnetic field).

\section{Results}

Upon demonstrating the two Java applets, a survey of how these applets helped in the understanding of the concept was made and some of the comments from them are as written below. A general observation is that the students seem to have had fairly a good conceptual understanding which helped them to solve problems in these chapters very easily. The students seem to be comfortable in successfully attempting problems in this area and their confidence has been built upon the conceptual understanding.

\subsection{Student hand written comments from an evaluation survey}

The following are some of the students' comments after they viewed the applet in the topical area of interest:

- The software that was displayed showed the relationship of Faraday's Law relationship.

- It is a fine job which could be used to demonstrate the faradays concept in class.

- The ring shown could also have an illustration of when the width varies. The $r$ (radius of the ring) varying shows a good emphasis on the relationship to area. However, the presentation overall was impressive. Both graph windows and loop should be combined for clarification.

- $\quad$ Nice presentation but it only makes meaning to those who have taken a course in physics and knows something about magnetic fields lines. It does not show in which direction the current is flowing. It does not also show the 
relationship with the number of turns in the coil. Overall it explains the Faradays Law.

- It is understandable for people with prior knowledge or at least any knowledge in physics.

- The applet gives a clear understanding and of how the Faradays Law is applied.

- Yes it is understandable but not too clear for the people who don't have an understanding of Faraday's Law. It is easy to use and interpret.

- It is really perfect, it does make the Faradays concept simpler to grasp.

- I have not been introduced to the law, however from the applet, as the green arrows change direction; the curve also changes from positive to negative. And for the triangle graph, there seems to be a negative value for the emf.

\section{Conclusion}

Engineering education plays a vital role in the production of human capital resources. Several thrust areas of engineering such as petroleum and chemical engineering need to be high on the priority. An urban city with enough technical and engineering talent will attract much needed foreign investments thereby spreading or diversifying its dependence on its natural resources and also improving the quality of life of each and every constituent of the urban society. Challenges of the $21^{\text {st }}$ century require students to be equipped with the creative talents in order that they are competitive. Teaching methods also needs to be more engaged so that it nurtures the necessary traits.

\section{References}

[1] Larkin, J. H, McDermott, J, Simon, D. P, \& Simon, H. A., Models of competence in solving physics problems, Cognitive Science, 4, pp. 317-345, 1980.

[2] Maloney. D., Research on alternative conceptions in science, In Handbook of Research on Science Teaching and Learning, Dorothy L. Gabel, ed. Washington. D.C. National Science Teachers Association, 1994.

[3] Simon, D. P., \& Simon, H. A., Individual differences in solving physics problems in Children's Thinking: What Develops? Robert S. Siegler, ed. Hillsdale, NJ. Lawrence Erlbaum, 1978.

[4] Ramalingam. P., New pedagogy for teaching physics - clickers, presented at School Science Teachers Annual Conference, Doha, Qatar. 2008. 